\title{
Tio2 as a Nanocarrier of Antibiotics (Quinolones): A Molecular Docking Assay
}

\author{
Esthela Paola García-Tejada ${ }^{1}$, Ángel Albino-Flores ${ }^{1}$, Jorge Emmanuel Mejía-Benavides², \\ Lucero Fuentes-Ocampo ${ }^{2}$, Erik Diaz-Cervantes ${ }^{*}$ \\ ${ }^{1}$ Departamento de Alimentos, Centro Interdisciplinario del Noreste (CINUG), Universidad de Guanajuato, 37975 Tierra \\ Blanca, Guanajuato, México.e.diaz@ugto.mx* \\ ${ }^{2}$ Departamento de Enfermería y Obstetricia, Centro Interdisciplinario del Noreste (CINUG), Universidad de \\ Guanajuato, 37975 Tierra Blanca, Guanajuato, México
}

\begin{abstract}
The state of the art about antibiotics shows that these compounds have been used frequently for the patients as a selfmedication or leave the treatment, which has promoted a bacterial resistance process. Regards above, it is clear that computational chemistry allows to explore new possibilities about the drug delivery, promoting a high bioavailability and selectivity in the biological targets. At the same time, is well known the use of nanocarriers for the effective transport of drugs and avoid the bacterial resistance. Int his order, in the present work has been modelled a family of nanocarriers based on $\mathrm{TiO}_{2}$ and three quinolones (moxifloxacin, trovafloxacin and sparfloxacin), which have been docked into the DNA gyrase. The results shown, that the proposed nanocarriers present an exergonic behaviour when were coupled with the selected target, being the best the Moxifloxacin- $\mathrm{TiO}_{2}$ composite, with a coupling energy of $165.48 \mathrm{kcal} / \mathrm{mol}$. Despite this work can be considered as a first approach of the proposed nano-systems, these obtained interactions can model the possible first step to deliver antibiotics in some bacterial resistance process.
\end{abstract}

Keywords: $\mathrm{TiO}_{2}$, Nanocarrier, Quinolone, Docking-assays, Adsorption-energy.

\section{Introduction}

Bacterial resistance is an emerging problem that has increased over time due to the protection mechanism, mutation, and bacterial metabolism changes. One of the more critical bacteria is Staphylococcus aureus, a pathogen microorganism that has modified its defense mechanisms, promoting resistance to methicillin. Statistics studies of the population in EUA show that $60 \%$ of $S$. aureus present resistant to methicillin (MRSA), triggering high amounts of morbidity and mortality in the hospitalization of patients who are not immunosuppressed or in chemotherapy treatment $[1,2]$.

Extrapolating the behaviour of resistant pathogen microorganisms, the low efficacy of antibiotics and, the high doses administrated against the resistance groups of bacterial allow us to visualize a difficulty in eradicating infections that today is easy to eliminate. The bioavailability of drugs, administration, and recognition efficiency between drug and biological targets is essential to optimize their function. In this order, nanotechnology is a hopeful field to study the decrease the weakness about the efficient delivery of drugs [3,4], specifically the interactions of nanocarriers and molecular targets.

One alternative is the design of inorganic nanocarriers of $\mathrm{TiO}_{2}$ as selective and efficient vectors to deliver the drug due to its properties of a large superficial area, small size, high stability, and low cost of production [5, 6]. Another beneficial characteristic of using $\mathrm{TiO}_{2}$ nanocarriers is the increase of half-life of the drug in the bloodstream, increasing their efficiency with lower doses. Based on the research of optimal drug delivery using nanotechnology, the present work aims to explore the composites quinolone- $\mathrm{TiO}_{2}$ complexed with the DNA gyrase of $S$. aureus (PDB code: 5CDP) [7] and computed their coupling energies to understand through a molecular docking assay a possible drug delivery nanocarrier. 


\section{Results And Discussion}

The structures of $\mathrm{TiO}_{2}$ and quinolones (Moxifloxacin, Trovafloxacin and Sparfloxacin) were modelled and optimized using the software and level of theory specified in the computational methods section, see figure 1.

A

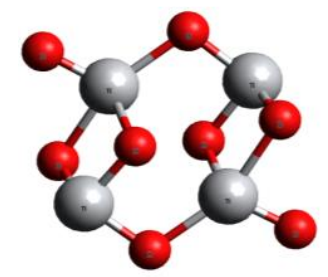

B

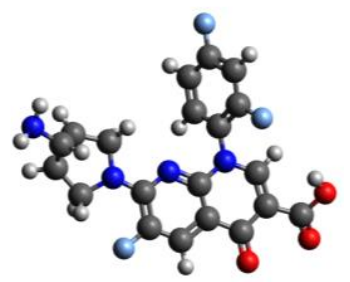

$\mathrm{C}$

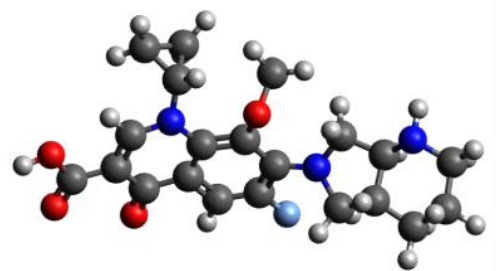

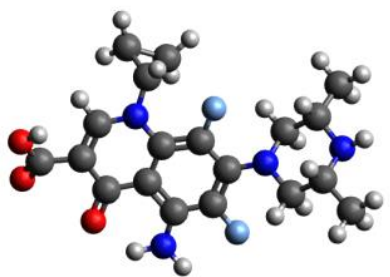

Fig. 1: Optimized structures of A) Titanium dioxide $\left(\mathrm{TiO}_{2}\right)$; B) Trovafloxacin (Tro); C) Moxifloxacin (Mox); and D) Sparfloxacin (Spa)

The Molegro virtual docker (MVD) was used to perform the docking assay, which computed the coupling energies of each studied molecule with the DNA gyrase; this energy was computed using Eq.1. The results show that the $\mathrm{Mox}-\mathrm{TiO}_{2}$ complex docked better to the DNA, with coupling energy of $-165.48 \mathrm{kcal} / \mathrm{mol}$, promoting the highest good coupling. The complex Tro- $\mathrm{TiO}_{2}$ interacts with the DNA, promoting an exergonic reaction with -152.42 $\mathrm{kcal} / \mathrm{mol}$, and finally, the complex $\mathrm{Spa}-\mathrm{TiO}_{2}$ presents $-142.92 \mathrm{kcal} / \mathrm{mol}$, see figure 2 . Note that the energies obtained present an exergonic behaviour; therefore, quinolone- $\mathrm{TiO}_{2}$ composites show increased interactions with biological targets, unlike the free molecules.
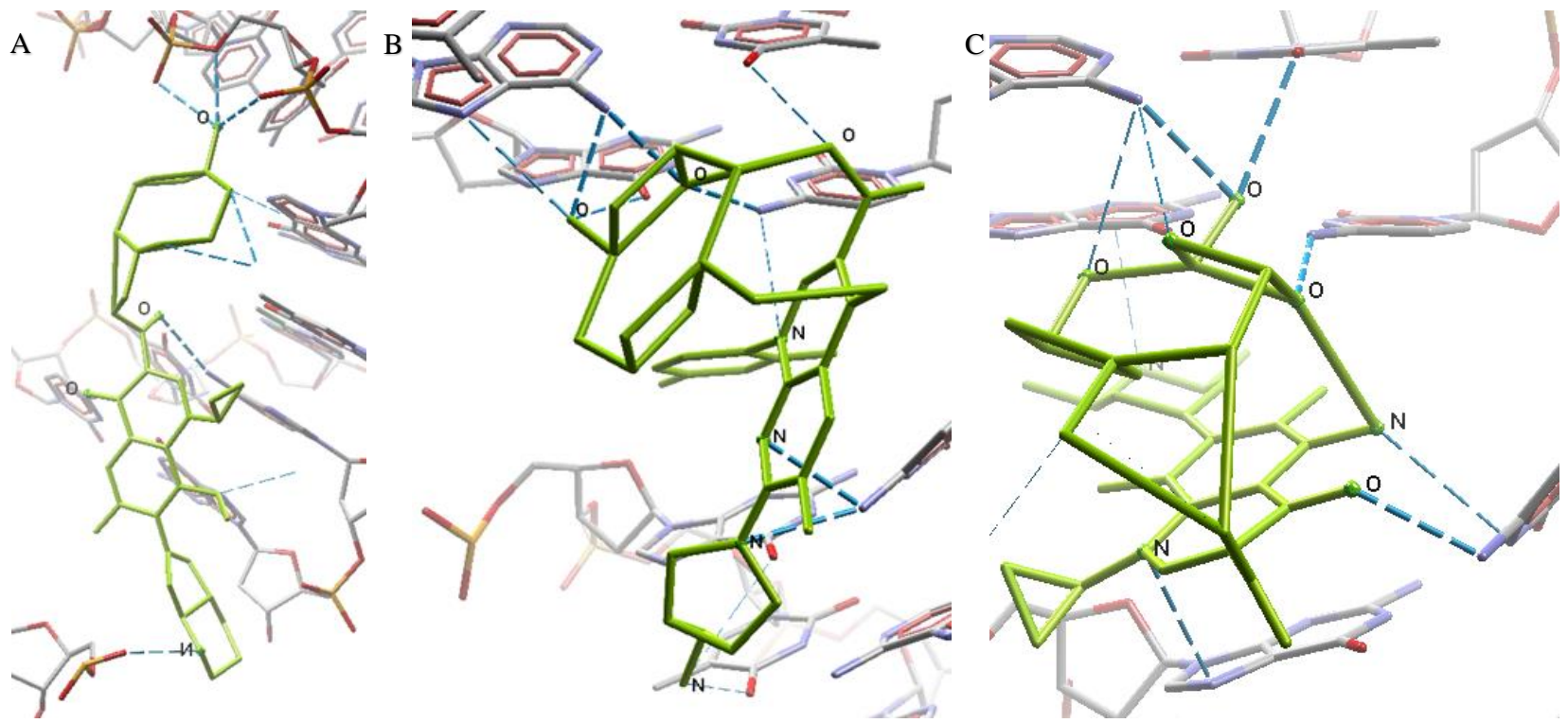

Fig. 2: Molecular docking of the DNA gyrase with A) $\mathrm{Mox}-\mathrm{TiO}_{2}$, B) $\mathrm{Tro}-\mathrm{TiO}_{2}$ and C) $\mathrm{Spa}^{-\mathrm{TiO}_{2}}$.

Figure 2 shows that the composite $\mathrm{Mox}-\mathrm{TiO}_{2}$ presents seven hydrogen bonds with the DNA components, and Tro$\mathrm{TiO}_{2}$ interacts with ten hydrogens with the same target. Finally, the $\mathrm{Spa}_{-} \mathrm{TiO}_{2}$ composite depicts eight hydrogen bond interactions. 
Finally, the overlay interactions shown in the docking represent the overlaying between DNA (phosphate and nitrogen) and quinolone- $\mathrm{TiO}_{2}$ system (mainly aromatic rings), suggesting a stacking interaction, see Figure 3.

$$
\mathrm{E}_{\text {coupling }}=E_{\text {composite }}-\left(E_{\text {quinolone }}+E_{\mathrm{TiO}_{2}}\right)
$$
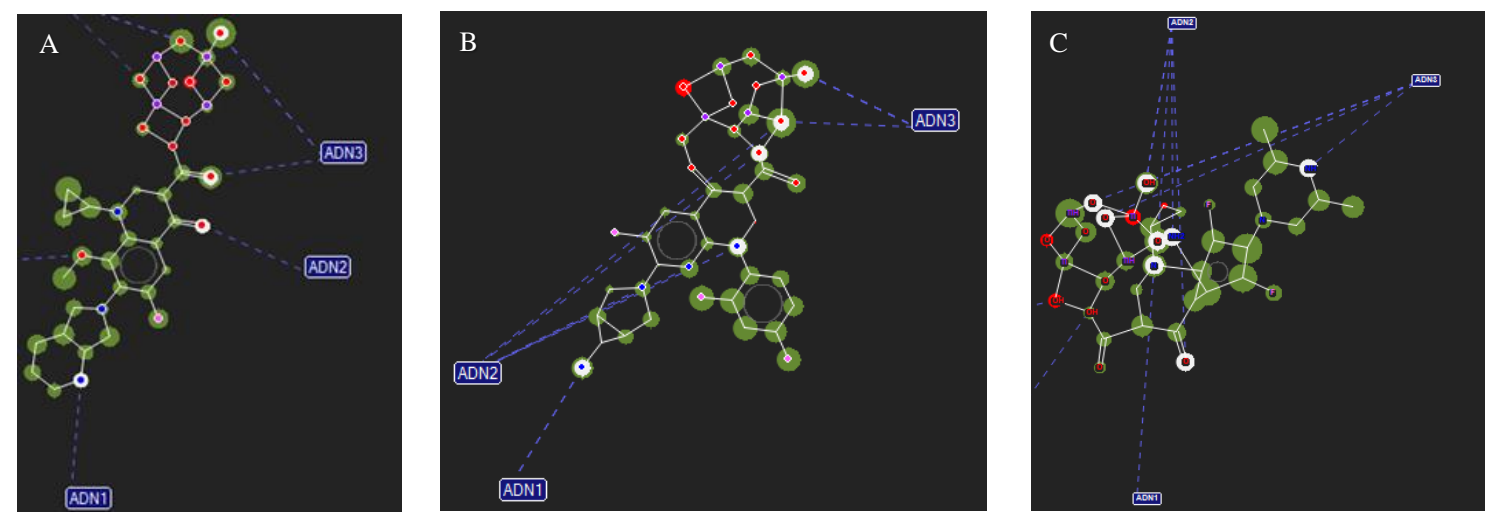

Fig. 3: Overlay interactions for A) $\mathrm{Mox}_{-} \mathrm{TiO}_{2}$, B) $\mathrm{Tro}_{-} \mathrm{TiO}_{2}$ and, C) $\mathrm{Spa}_{-} \mathrm{TiO}_{2}$.

\section{Computational Methods}

The whole molecules were modelled using the Avogadro package [8]; at the same time, the optimization was performed through the DFT formalism [9] using the Gaussian software [10], at level M06L/6-31G(d,p) [11]. Finally, the molecular docking was performed using the Molegro virtual Docker (MDV) [12], and the molecules were visualized using Gauss view [13] and Avogadro.

\section{Conclusions}

Computational chemistry provides an approach to the molecular behaviour and several systems in the present work, which allows knowing the interactions between the quinolone- $\mathrm{TiO}_{2}$ composites with the DNA gyrase chain of $S$. aureus. The proposed nanocarriers shown an exergonic behaviour coupled with the selected target; the best $\mathrm{Mox}_{-} \mathrm{TiO}_{2}$ composite, with coupling energy of $-165.48 \mathrm{kcal} / \mathrm{mol}$. Although this work can be considered a first approach to the proposed nano-systems, these obtained interactions can model the possible first step to deliver antibiotics in some bacterial resistance processes.

\section{Acknowledgements}

We are acknowledged to the Laboratorio Nacional de Caracterización de Propiedades Fisicoquímicas y Estructura Molecular (UG-CONACyT, Project: 2019-000037-02NACF-12250) for the computing time provided at the PIPILA cluster.

\section{References}

[1] F. Angulo, V. Nargund, and T. Chiller, "Evidence of an association between use of anti-microbial agents in food animals and anti-microbial resistance among bacteria isolated from humans and the human health consequences of such resistance," Journal of Veterinary Medicine, Series B, vol. 51, no. 8-9, pp. 374-379, 2004.

[2] S. B. Levy, "Antibiotic Resistance: Consequences of Inaction," Clinical Infectious Diseases, vol. 33, no. Supplement_3, pp. S124-S129, 2001, doi: 10.1086/321837.

[3] Y.-Y. Song, F. Schmidt-Stein, S. Bauer, and P. Schmuki, "Amphiphilic TiO2 Nanotube Arrays: An Actively Controllable Drug Delivery System," Journal of the American Chemical Society, vol. 131, no. 12, pp. 4230-4232, 2009/04/01 2009, doi: 10.1021/ja810130h.

[4] H. A. M. Faria and A. A. A. de Queiroz, "A novel drug delivery of 5-fluorouracil device based on TiO2/ZnS nanotubes," Materials Science and Engineering: $C$, vol. 56, pp. 260-268, 2015/11/01/ 2015, doi: https://doi.org/10.1016/j.msec.2015.06.008. 
[5] L. Ding, Jiawei Li, Rui Huang, Zhidong Liu, Chunhua Li, Shaozi Yao, Jinyan Wang, Dongli Qi, Nan li, Jiaxin Pi; "Salvianolic acid B protects against myocardial damage caused by nanocarrier $\mathrm{TiO} 2$; and synergistic anti-breast carcinoma effect with curcumin via codelivery system of folic acid-targeted and polyethylene glycol-modified TiO2 nanoparticles," International journal of nanomedicine, vol. 11, p. 5709, 2016.

[6] X. Chen and A. Selloni, "Introduction: Titanium Dioxide (TiO2) Nanomaterials," Chemical Reviews, vol. 114, no. 19, pp. 9281-9282, 2014/10/08 2014, doi: 10.1021/cr500422r.

[7] Pan F. Chan, Velupillai Srikannathasan, Jianzhong Huang, Haifeng Cui, Andrew P. Fosberry, Minghua Gu, Michael M. Hann, Martin Hibbs, Paul Homes, Karen Ingraham, Jason Pizzollo, Carol Shen, Anthony J. Shillings, Claus E. Spitzfaden, Robert Tanner, Andrew J. Theobald, Robert A. Stavenger, Benjamin D. Bax, Michael N. Gwynn; "Structural basis of DNA gyrase inhibition by antibacterial QPT-1, anticancer drug etoposide and moxifloxacin," Nature communications, vol. 6, no. 1, pp. 1-13, 2015.

[8] M. D. Hanwell, D. E. Curtis, D. C. Lonie, T. Vandermeersch, E. Zurek, and G. R. Hutchison, "Avogadro: an advanced semantic chemical editor, visualization, and analysis platform," Journal of Cheminformatics, vol. 4, no. 1, p. 17, 2012/08/13 2012, doi: 10.1186/1758-2946-4-17.

[9] R. G. Parr and W. Yang, Density-functional theory of atoms and molecules. Oxford university press, 1989.

[10] G. W. T. M. J. Frisch, H. B. Schlegel, G. E. Scuseria, M. A. Robb, J. R. Cheeseman, G. Scalmani, V. Barone, G. A. Petersson, H. Nakatsuji, X. Li, M. Caricato, A. Marenich, J. Bloino, B. G. Janesko, R. Gomperts, B. Mennucci, H. P. Hratchian, J. V. Ortiz, A. F. Izmaylov, J. L. Sonnenberg, D. Williams-Young, F. Ding, F. Lipparini, F. Egidi, J. Goings, B. Peng, A. Petrone, T. Henderson, D. Ranasinghe, V. G. Zakrzewski, J. Gao, N. Rega, G. Zheng, W. Liang, M. Hada, M. Ehara, K. Toyota, R. Fukuda, J. Hasegawa, M. Ishida, T. Nakajima, Y. Honda, O. Kitao, H. Nakai, T. Vreven, K. Throssell, J. A. Montgomery, Jr., J. E. Peralta, F. Ogliaro, M. Bearpark, J. J. Heyd, E. Brothers, K. N. Kudin, V. N. Staroverov, T. Keith, R. Kobayashi, J. Normand, K. Raghavachari, A. Rendell, J. C. Burant, S. S. Iyengar, J. Tomasi, M. Cossi, J. M. Millam, M. Klene, C. Adamo, R. Cammi, J. W. Ochterski, R. L. Martin, K. Morokuma, O. Farkas, J. B. Foresman, and D. J. Fox., "Gaussian 09," in Revision A.02, ed. Gaussian Inc.

[11] D. G. Gusev, "Assessing the Accuracy of M06-L Organometallic Thermochemistry," Organometallics, vol. 32, no. 15, pp. 4239-4243, 2013/08/12 2013, doi: 10.1021/om400412p.

[12] C. M. Thomsen R, "MolDock: a new technique for high-accuracy molecular docking.," Journal of Medicinal Chemistry vol. 49, pp. 3315-3321, 2006.

[13] R. Dennington, "II; Keith, TA; Millam, JM GaussView 5.0. 8; Gaussian," Inc., Wallingford, CT, 2008. 